\title{
The Phantom Cow Syndrome: Risk factors for and reproductive outcomes of Phantom cows on New Zealand dairy farms
}

\section{EL Cuttance $^{* \S 1}$ and WA Mason ${ }^{*}$}

${ }^{*}$ VetEnt, 49 Benson Road, Te Awamutu 3800, New Zealand

sAuthor for correspondence. Email: emma.cuttance@vetent.co.nz

Supplementary Figure 1. Predictive probability of becoming a phantom cow of different combinations of all the identified risk factors from the multivariate model.

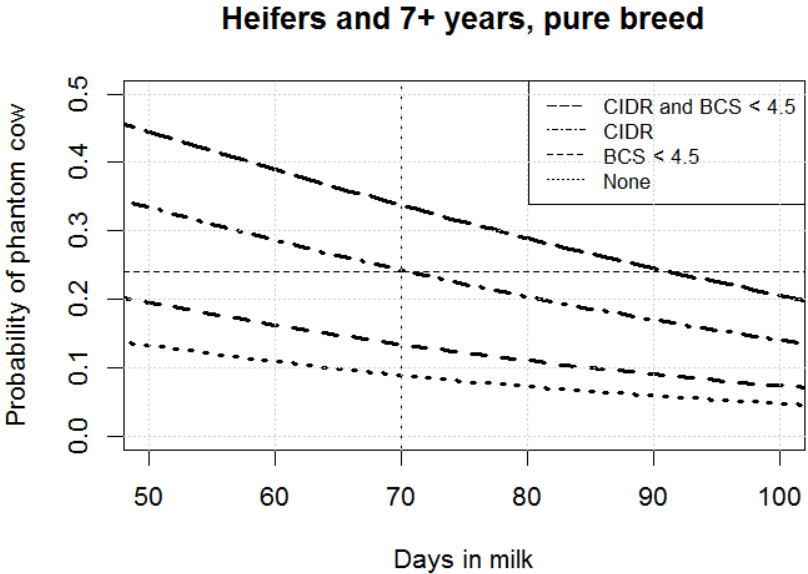

Heifers and $7+$ years, cross breed

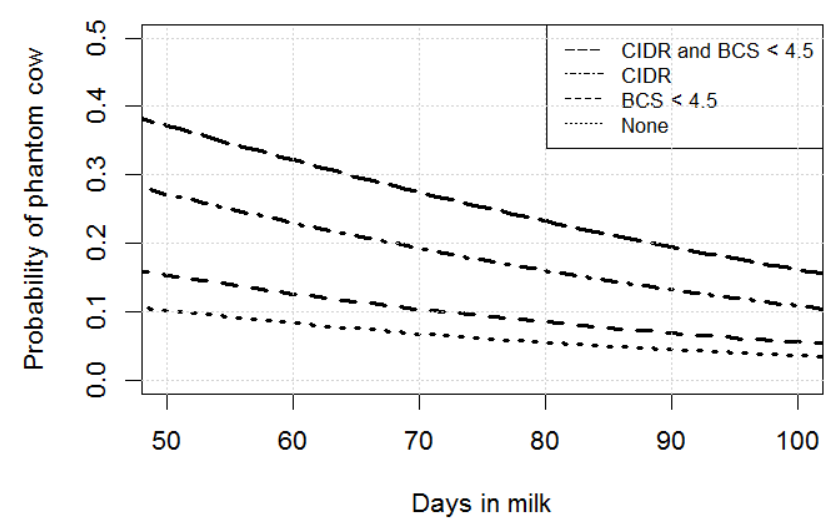

3-6 year olds, pure breed

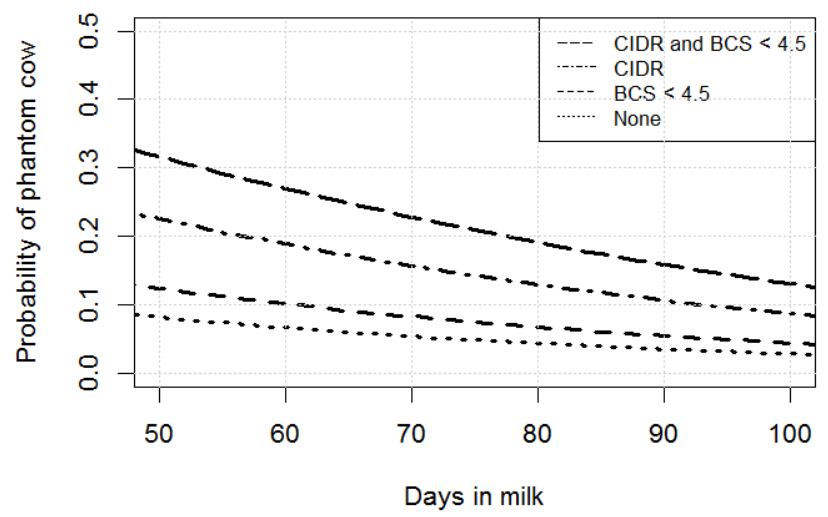

3-6 year olds, cross breed

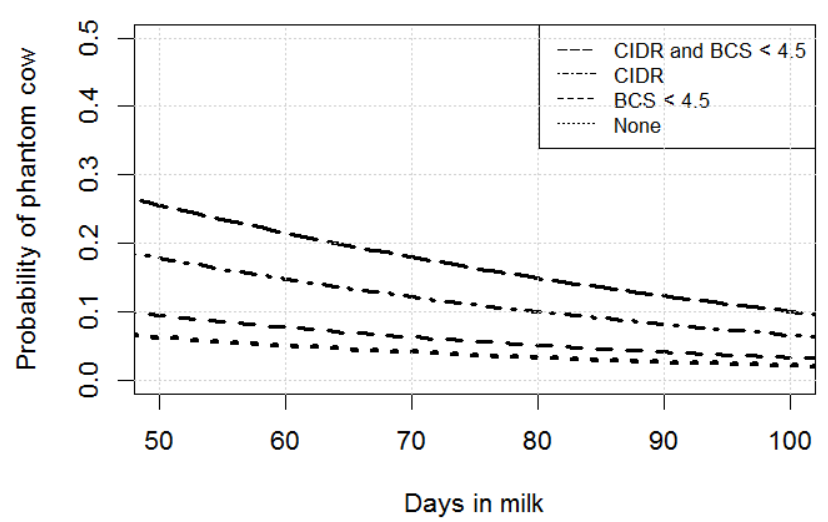

CIDR=cows treated with a CIDR device prior to, or at the start of mating; $B C S<4.5=$ cows with $B C S<4.5$ at the start of mating; None=cows that were not treated with a CIDR device and had a BCS $>=4.5$ at the start of mating; pure breed=cow that is $>13 / 16$

\footnotetext{
${ }^{1}$ The content of this supplementary information has not been edited. All risk and liability rest with the authors.
} 